\title{
Processos de discussão em espaços públicos: a gestão social dos Conselhos Municipais de Desenvolvimento do Noroeste Colonial do Estado do Rio Grande do Sul - Brasil'
}

Jean Pierre Chassot ${ }^{2}$

Sérgio Luis Allebrandt ${ }^{3}$

\section{Resumo}

O estudo busca analisar a gestão social sob os aspectos habermasianos de cidadania deliberativa, que possui como base o diálogo e a interação, e é caracterizada como uma gestão pública voltada para os interesses públicos, onde os envolvidos têm o direito de participar, junto aos Conselhos Municipais de Desenvolvimento (Comudes) dos municípios que integram o Conselho Regional de Desenvolvimento do Noroeste Colonial (Corede- Norc) do Estado do Rio Grande do Sul - Brasil. A pesquisa objetiva analisar a organização e o funcionamento dos Comudes como conselhos gestores das políticas públicas nos municípios pertencentes ao Corede-Norc, visando ao fortalecimento da cidadania a fim de promover o desenvolvimento da região em questão. A metodologia utilizada foi a de uma abordagem qualitativa, buscando identificar a prática efetiva do conceito de gestão social com cidadania deliberativa por meio de entrevistas com os atores envolvidos no processo e análise da legislação. O diagnóstico dos dados foi realizado conforme matriz de análise baseada nos estudos de Tenório (2012), em que a legitimidade das decisões políticas deve ter origem em processos de discussão. Os resultados mostraram que, apesar dos Comudes não atingirem o ideal habermasiano, ficou clara a evolução destes espaços na condução dos processos de tomada de decisão descentralizada, mostrando o esforço que os atores dedicam à consecução de uma gestão envolvente, na tentativa de mobilizar cada vez mais a sociedade para melhorar constantemente os resultados que a gestão pública implica no cotidiano da população.

\footnotetext{
${ }^{1}$ Uma versão inicial deste trabalho foi apresentado no VII SIDR (Seminário Internacional Sobre Desenvolvimento Regional), cujo tema foi "Globalização em tempos de Regionalização repercussões no território", realizado no período de 9 a 11 de setembro de 2015, na cidade de Santa Cruz do Sul, Rio Grande do Sul - Brasil.

${ }^{2}$ Mestre em Desenvolvimento. Professor da Faculdade de Ciências do Tocantins (FACIT) e do Instituto Dias de Ensino, Pesquisa e Pós-Graduação (IDESP). jeanchassot@hotmail.com.

${ }^{3}$ Doutor em Desenvolvimento Regional. Professor do Departamento de Estudos da Administração da Universidade Regional do Noroeste do Estado do Rio Grande do Sul - UNIJUI.

allebr@unijui.edu.br
} 
Palavras-chave: Gestão Social. Cidadania Deliberativa. Conselhos Gestores. Políticas Públicas. Desenvolvimento Regional.

\begin{abstract}
The study seeks to analyze the social management under the Habermasians aspects of deliberative citizenship that has as base the dialogue and interaction, which is characterized as a dedicated public management to the public interest where those involved have the right to participate, with Municipal Councils Development (COMUDEs) of the municipalities making up the Regional Development Council Colonial Northwest (Corede- NORC) the State of Rio Grande do Sul, Brazil. The research aims to analyze the organization and functioning of COMUDEs as management councils of public policies in the municipalities belonging to COREDE-NORC, aimed at strengthening citizenship in order to promote the development of the region in question. The methodology used was a qualitative approach in order to identify effective practice of the concept of social management with deliberative citizenship through interviews with the actors involved in the process and analysis of the legislation. The diagnosis of the data was performed as analysis matrix based on the studies of Tenorio (2012), in which the legitimacy of political decisions must come from discussion threads. The results showed that despite the COMUDEs not reach the Habermasian ideal showed a clear evolution of these spaces in the conduct of decentralized decision-making processes, showing the effort that the actors dedicated to achieving an environment management in an attempt to mobilize each again the company to constantly improve the results the public administration implies the daily life of the population.
\end{abstract}

Keywords: Social Management. Deliberative Citizenship. Management Councils. Public policy. Regional development.

\title{
1 Introdução
}

O estudo tem como tema a gestão social, orientado pelo aspecto habermasiano de cidadania deliberativa, que possui como base o diálogo e a interação, e é caracterizada como uma gestão pública voltada para os interesses públicos da população, da coletividade, da sociedade, onde todos os envolvidos têm o direito a participar.

Para Tenório (2008), a gestão social é o processo gerencial dialógico em que a autoridade decisória é compartilhada entre os participantes da ação, ou seja, é um espaço onde todos têm direito à fala, sem nenhum tipo de coação. Para ele, o conceito de gestão social está apoiado na compreensão da inversão dos seguintes pares de palavras: estado-sociedade; capital-trabalho; sociedade e mercado, e no conceito de cidadania deliberativa. Para Tenório, cidadania deliberativa significa "[...] que a legitimidade das decisões políticas deve ter origem em processo de discussão, orientados pelos princípios da inclusão, do pluralismo, da igualdade participativa, da autonomia e do bem comum" (2008, p. 161). Por isso, este estudo considera o conceito de gestão social aos olhos do teórico Fernando Guilherme Tenório, que estuda 
a gestão social com cidadania deliberativa (TENÓRIO, 2010; 2011).

O estudo foi desenvolvido junto aos Conselhos Municipais de Desenvolvimento (Comudes) dos municípios que integram o Conselho Regional de Desenvolvimento do Noroeste Colonial (Corede-Norc) do estado do Rio Grande do Sul. Procurando conhecer a realidade dos conselhos, objetivou-se mostrar as dinâmicas de discussões estabelecidas nesses espaços. Para tanto, o recorte temporal utilizado para elucidar a problemática foi correspondente à gestão administrativa dos municípios, nos anos de 2009 a 2012, e assim buscou-se responder à seguinte pergunta: Os Comudes dos municípios do Corede-Norc, como conselhos gestores de políticas públicas, estão estruturados para o fortalecimento da cidadania, tendo como consequência a promoção do desenvolvimento, considerando o contexto organizacional dos mesmos e as políticas transversais existentes dentro do território em questão?

Para responder a essa questão, estabeleceu-se como objetivo analisar os processos de discussões realizados nos Conselhos Municipais de Desenvolvimento (Comudes) nos municípios pertencentes ao Corede-Norc, visando ao fortalecimento da cidadania a fim de promover o desenvolvimento da região. Para tanto, buscou-se conhecer e analisar os procedimentos decisórios desenvolvidos nestes espaços públicos e a condução das políticas públicas locais, pois a discussão constitui o diálogo que verbaliza a compreensão que cada um tem no objeto em análise.

\section{Comudes dos municípios que compõem o Corede-Norc}

Os Comudes passaram a fazer parte da dinâmica social dos municípios da região Noroeste Colonial, a partir de 2003, cuja data e lei, em vigência, de criação dos conselhos verificam-se no Quadro 1. Nesse ano, houve um processo de criação/recriação e revitalização destes espaços, em função de que os Coredes e o Fórum dos Coredes, juntamente com o governo do Estado da época (governo Rigotto), entenderam que a existência desse conselho deveria passar a ser uma pré-condição para os municípios participarem do Processo de Participação Popular, que veio substituir o instrumento de gestão participativa do Orçamento Participativo do governo anterior (governo Olívio Dutra).

Os Comudes que integram os municípios do Corede Noroeste Colonial, de acordo com suas leis de criação (Quadro 1, inserido na próxima página), são classificados como pessoa jurídica de direito privado, associação civil sem fins lucrativos, que conta com a representação e a participação da sociedade civil e das diferentes instâncias dos poderes públicos com sede em cada município.

As legislações que criam os Comudes estabelecem para estes como objetivo a promoção do desenvolvimento local, de forma harmônica e sustentável, através da integração das ações do poder público com as organizações privadas, as entidades da sociedade civil organizada e os cidadãos, visando à melhoria da qualidade de vida da população, à distribuição harmônica e equilibrada da economia e à preservação ambiental.

Aliada a este objetivo, que é comum para os onze Comudes, o Conselho de ljuí ainda inclui a viabilização à participação dos cidadãos e das organizações da so- 
ciedade local na gestão do plano municipal de desenvolvimento, onde o conselho constitui-se num espaço de construção da cidadania interativa e de promoção da articulação entre as entidades e os demais conselhos setoriais e temáticos do município, para propor ações aos poderes públicos municipal, estadual e federal, visando ao desenvolvimento harmônico e integrado; à elaboração e priorização de projetos a serem propostos pela comunidade ijuiense junto ao Corede e às demais instâncias de discussão e de deliberação popular e participativa; ao fortalecimento da cultura e a vivência da participação democrática na gestão da comunidade local; à promoção da disseminação das informações relevantes para o desenvolvimento local e regional no intuito de qualificar a participação.

\section{Quadro 1 - Legislação que cria os Comudes da região Noroeste Colonial}

\begin{tabular}{|l|c|c|}
\hline \multicolumn{1}{|c|}{ Município } & Lei Municipal & Data \\
\hline Ajuricaba & 1.454 & $24 / 06 / 2003$ \\
\hline Augusto Pestana & 770 & $19 / 11 / 2003$ \\
\hline Bozano & 162 & $28 / 05 / 2003$ \\
\hline Catuípe & 1.303 & $27 / 06 / 2003$ \\
\hline Condor & 1.365 & $03 / 07 / 2003$ \\
\hline Coronel Barros & 630 & $24 / 06 / 2003$ \\
\hline ljuí & 4.046 & $17 / 12 / 2002$ \\
\hline Jóia & 1.397 & $16 / 06 / 2003$ \\
\hline Nova Ramada & 1.096 & $09 / 09 / 2011$ \\
\hline Panambi & 2.201 & $26 / 06 / 2003$ \\
\hline Pejuçara & 1.093 & $25 / 11 / 2003$ \\
\hline
\end{tabular}

Fonte: Elaborado pelos autores.

Os Comudes têm como competências comuns em suas leis promover a participação de todos os segmentos da sociedade local, organizados ou não, na discussão dos problemas e na identificação das potencialidades, bem como na definição de políticas públicas de investimento e ações que visem ao desenvolvimento econômico e social dos municípios; organizar e realizar as audiências públicas necessárias, em que a sociedade local discutirá e elegerá as prioridades municipais; elaborar o Plano Estratégico de Desenvolvimento Municipal; promover e fortalecer a participação da sociedade civil, para buscar a sua integração regional; realizar a interface com as atividades do Corede-Norc, buscando articulação com o Estado; constituir espaço de discussão e formulação de propostas para servirem como subsídio à elaboração dos Planos Plurianuais (PPA), Leis de Diretrizes Orçamentárias (LDO) e dos Orçamentos Anuais (LOAs) municipais e estadual, bem como articular políticas públicas voltadas ao desenvolvimento; acompanhar e fiscalizar a execução das ações ou investimentos escolhidos no Comude e incluídos nos orçamentos municipais ou estadual. 
A estrutura organizacional dos Comudes, com exceção a do município de ljuí, possui a seguinte composição: I - Assembleia Geral; II - Conselho de Representantes; e III - Diretoria Executiva. A Assembleia Geral dos Comudes, com exceção da de ljuí, que possui uma estrutura diferenciada dos demais, o que será analisado a seguir, é o órgão máximo de deliberação do conselho e é constituída por todos os cidadãos que comprovem, através de seu título eleitoral, domicílio no município em questão, e cuja participação será precedida de credenciamento. Tem como competências eleger, para mandato de dois anos, entre os membros da Assembleia Geral, os integrantes do Conselho de Representantes; identificar, discutir e aprovar, por meio de audiências públicas, as prioridades municipais, estimulando e orientando as atividades e os investimentos socioeconômicos nos municípios; discutir e aprovar as diretrizes gerais da política de desenvolvimento de cada município; e aprovar o estatuto do conselho, bem como modificá-lo no que couber. Somadas a essas competências, o Comude de Pejuçara ainda inclui apreciar e deliberar sobre o relatório anual do Conselho de Representantes; aprovar o Plano Estratégico de Desenvolvimento Municipal, elaborado de acordo com o Estatuto da Cidade; e apreciar e deliberar sobre propostas relacionadas com o PPA, LDO e orçamentos municipal, estadual e federal.

O Conselho de Representantes, órgão de segunda instância da estrutura organizacional dos Comudes dos municípios que pertencem ao Corede-Norc, e novamente com exceção de ljuí, possuem como competências eleger, dentre os seus membros, a Diretoria Executiva e o Conselho Fiscal; dar o devido encaminhamento às propostas decididas pela Assembleia Geral; oferecer suporte à Assembleia Geral e à Diretoria Executiva, elaborando planos, projetos e programas; criar Comissões Setoriais ou de estudo e planejamento, fomentando as suas ações e promovendo a integração municipal; decidir "ad referendum" da Assembleia Geral casos urgentes ou omissos; e aprovar, quando couber, as contas apresentadas pela Diretoria Executiva, bem como o orçamento para o exercício seguinte. Os mandatos dos membros do Conselho de Representantes terão a duração de dois anos, permitida a reeleição.

A Diretoria Executiva, outro órgão da estrutura dos Comudes da região, novamente com exceção do município de ljuí, é o órgão gestor das ações desenvolvidas pela Assembleia Geral e pelo Conselho de Representantes. É composta pelo presidente, vice-presidente, $1^{\circ}$ tesoureiro, $2^{\circ}$ tesoureiro, $1^{\circ}$ secretário e $2^{\circ}$ secretário, que são eleitos dentre os integrantes do Conselho de Representantes do Comude para um mandato de dois anos, sendo permitida a reeleição.

Entre as competências legais da Diretoria Executiva estão a de dirigir a assembleia geral, coordenar as audiências públicas, bem como as consultas aos cidadãos; encaminhar ao Corede-Norc a relação das prioridades locais identificadas na assembleia geral, com vistas à inclusão na proposta orçamentária do Estado, e, ainda, realizar no mínimo uma assembleia geral ao ano, quando do levantamento de propostas para a Lei de Orçamento Anual (LOA).

Nestes municípios, a Assembleia Geral, o Conselho de Representantes e a Diretoria Executiva reúnem-se, ordinária ou extraordinariamente, mediante convocação. E, ainda, as reuniões realizadas são registradas em ata, com nominata dos participantes. Salienta-se que a participação da população nos Comudes é considerada 
função pública relevante, sendo vedada a remuneração.

A estrutura do Conselho de Desenvolvimento de ljuí (Codemi) é um pouco diferenciada, pois é composta por I - Fórum Municipal de Desenvolvimento; II - Assembleia do Codemi; III - Conselho Diretor; IV - Núcleo de Coordenação; V - Comissões Permanentes; e VI - Comissões Temáticas Especiais. O Fórum Municipal de Desenvolvimento de ljuí constitui-se no espaço público mais amplo para a discussão comunitária da problemática e das potencialidades do desenvolvimento local e regional, com vistas à definição das diretrizes estratégicas para orientar o Plano Estratégico Participativo de ljuí. É composto por todas as entidades que integram a Assembleia do Codemi, outras entidades não credenciadas para a Assembleia e os cidadãos interessados na discussão do desenvolvimento. Reúne-se ordinariamente no terceiro bimestre de cada ano. E é instalado através de edital, contendo uma programação expedida conjuntamente pelo Prefeito de ljuí e pelo Coordenador do Codemi.

A Assembleia do Codemi tem as seguintes atribuições: I - eleger os membros não natos do Conselho Diretor; II - apreciar e deliberar sobre o Plano Estratégico de Desenvolvimento de ljuí; III - discutir e deliberar sobre assuntos demandados pelo conselho. A Assembleia do Codemi reúne-se ordinariamente uma vez por semestre, por convocação do Coordenador, e é composta por membros natos e representantes de órgãos e/ou entidades organizadas no município que se cadastrem para integrá-la.

\section{Metodologia}

Para elucidar a questão norteadora e atingir os objetivos propostos, adotou-se uma abordagem qualitativa, que, de acordo com Minayo (1999, p. 57), "[...] se aplica ao estudo da história, das relações, das representações, das crenças, das percepções e das opiniões, produtos das interpretações que os humanos fazem a respeito de como vivem, constroem seus artefatos e a si mesmos, sentem e pensam".

Para a realização da pesquisa, fez-se uso da técnica de pesquisa documental, como, por exemplo, atas de reuniões, documentos e relatórios emitidos, e outras formas de registro de atividade dos Comudes, assim como das legislações municipais referentes aos conselhos, para contribuir no levantamento de informações sobre a ação dessa esfera pública. Também se optou pela realização de entrevistas semiestruturadas com representantes dos Comudes e executivos municipais, com a utilização de um Termo de Consentimento que visou ao esclarecimento dos sujeitos sobre a finalidade da pesquisa, o sigilo e a importância da sua colaboração e da participação para o referido estudo.

Foi utilizada a entrevista semiestruturada, pois permite, segundo Marconi e Lakatos (2006), a liberdade para que o pesquisador desenvolva cada situação na direção que julgar adequada, e a utilização de perguntas abertas, que podem ser respondidas a partir de uma conversação informal. Para Duarte (2006, p. 63), na entrevista semiestruturada, "[...] as perguntas permitem explorar um assunto ou aprofundá-lo, descrever processos e fluxos, compreender o passado, analisar, discutir e fazer prospectivas".

A pesquisa também foi observacional, isto é, observou-se a atuação e o de- 
sempenho dos membros dos Comudes durante a sua participação em encontros realizados pelo Corede-Norc para a discussão dos desenvolvimentos local e regional. Essas observações foram realizadas no período de março de 2012 a junho de 2013, a partir de um primeiro contato, estabelecido por telefone, para agendamento de data e horário.

Destaca-se que foi garantida a representatividade nas entrevistas a cada um dos onze Comudes do Corede-Norc. Para tanto, optou-se pela identificação dos sujeitos entrevistados por meio de letras que representam o segmento e os seus municípios: por exemplo, no Conselho Municipal de Desenvolvimento de Bozano, representando o executivo municipal, utilizou-se a sigla PMBo, e assim sucessivamente, visando garantir o sigilo ético da pesquisa, conforme acordado com os sujeitos entrevistados durante a coleta de dados através do Termo de Consentimento.

A análise dos dados qualitativos da pesquisa ocorreu a partir da técnica de análise de conteúdo, orientada pela organização da análise ou pré-análise, a exploração ou codificação e depois o tratamento dos dados e resultados. Ou seja, para o tratamento das informações coletadas, utilizaram-se as categorias de análise segundo os estudos desenvolvidos pelo Programa de Estudos em Gestão Social (PEGS), vinculado à Escola Brasileira de Administração Pública e de Empresas da Fundação Getúlio Vargas (Ebape/FVG), que foram orientados teoricamente segundo o conceito habermasiano de cidadania deliberativa, termo que, segundo Tenório (2007, p. 54), significa que a "[...] legitimidade das decisões políticas deve ter origem em processos de discussão, orientados pelos princípios da inclusão, do pluralismo, da igualdade participativa, da autonomia e do bem comum". Seguindo esses princípios, o PEGS, que desenvolve estudos a partir dos preceitos teóricos de cidadania deliberativa de Habermas e de suas relações com os critérios de avaliação da participação cidadã, desenvolvidos com base nos critérios propostos pelo Instituto de Governo e Políticas Públicas (IGOP) da Universidade Autônoma de Barcelona, estabeleceu um conjunto de critérios para cada categoria.

Entre os diferentes modelos propostos por pesquisadores sociais, optou-se pelo critério PEGS, de acordo com a intencionalidade do pesquisador em obter as informações que satisfaçam os objetivos da pesquisa, pois o programa entende a gestão social como o processo gerencial dialógico, que compartilha a autoridade decisória entre os participantes da ação. Desde a sua criação, em 1990, esse programa desenvolve atividades a partir dos seguintes pares de palavras-categorias: estado-sociedade, capital-trabalho e mercado-sociedade, assim como gestão estratégica, gestão social e cidadania deliberativa. Portanto, o conceito de gestão social é baseado na compreensão da inversão desses pares de palavras e no conceito de cidadania deliberativa.

Para Tenório (2008), gestão social é o processo gerencial decisório deliberativo que procura atender às necessidades da sociedade, região, território ou sistema social específico, quer vinculado à produção de bens quer à prestação de serviços. Nesse sentido, com base nos critérios do autor, apresenta-se, no Quadro 2, a Matriz de Categorias e Critérios de análise de espaços públicos. 
Quadro 2 - Matriz de categorias e critérios de análise de espaços públicos

\begin{tabular}{|c|c|}
\hline Categorias & Critérios \\
\hline \multirow{7}{*}{$\begin{array}{l}\text { Processo de } \\
\text { discussão }\end{array}$} & $\begin{array}{l}\text { Canais de difusão: existência e utilização de canais adequados } \\
\text { ao acesso à informação para a mobilização dos potenciais } \\
\text { participantes. }\end{array}$ \\
\hline & $\begin{array}{l}\text { Qualidade da informação: diversidade, clareza e utilidade da } \\
\text { informação proporcionada aos atores envolvidos. }\end{array}$ \\
\hline & $\begin{array}{l}\text { Espaços de transversalidade: espaços que atravessam setores com } \\
\text { o intuito de integrar diferentes pontos de vista. }\end{array}$ \\
\hline & $\begin{array}{l}\text { Relação com outros processos participativos: interação com outros } \\
\text { sistemas participativos já existentes na região }\end{array}$ \\
\hline & $\begin{array}{l}\text { Órgãos existentes: uso de órgãos e estruturas já existentes, } \\
\text { evitando a duplicação das estruturas. }\end{array}$ \\
\hline & $\begin{array}{l}\text { Órgão de acompanhamento: existência de um órgão que faça o } \\
\text { acompanhamento de todo o processo, desde sua elaboração até } \\
\text { a implementação, garantindo a coerência e a fidelidade ao que foi } \\
\text { deliberado e de forma participativa. }\end{array}$ \\
\hline & $\begin{array}{l}\text { Pluralidade do grupo promotor: compartilhamento da liderança a } \\
\text { fim de reunir diferentes potenciais atores. }\end{array}$ \\
\hline \multirow{3}{*}{ Inclusão } & $\begin{array}{l}\text { Abertura dos espaços de decisão: processos, mecanismos, } \\
\text { instituições que favorecem a articulação dos interesses dos } \\
\text { cidadãos ou dos grupos, dando uma chance igual a todos de } \\
\text { participação na tomada de decisão. }\end{array}$ \\
\hline & $\begin{array}{l}\text { Aceitação social, política e técnica: reconhecimento pelos atores } \\
\text { da necessidade de uma metodologia participativa, tanto no } \\
\text { âmbito social quanto no político e no técnico. }\end{array}$ \\
\hline & $\begin{array}{l}\text { Valorização cidadã: valorização por parte dos cidadãos da } \\
\text { relevância da sua participação. }\end{array}$ \\
\hline Categorias & Critérios \\
\hline \multirow[t]{2}{*}{ Pluralismo } & $\begin{array}{l}\text { Participação de diferentes atores: atuação de associações, } \\
\text { movimentos e organizações, bem como de cidadãos não } \\
\text { organizados envolvidos no processo deliberativo. }\end{array}$ \\
\hline & $\begin{array}{l}\text { Perfil dos atores: características dos atores em relação às suas } \\
\text { experiências em processos democráticos de participação. }\end{array}$ \\
\hline \multirow{3}{*}{$\begin{array}{l}\text { Igualdade } \\
\text { Parecipa@va }\end{array}$} & $\begin{array}{l}\text { Forma de escolha dos representantes: métodos utilizados para a } \\
\text { escolha de representantes. }\end{array}$ \\
\hline & $\begin{array}{l}\text { Avaliação participativa: intervenção dos participantes no } \\
\text { acompanhamento e na avaliação das políticas públicas. }\end{array}$ \\
\hline & $\begin{array}{l}\text { Discurso dos representantes: valorização de processos } \\
\text { participativos nos discursos exercidos por representantes. }\end{array}$ \\
\hline
\end{tabular}

Continua na próxima página. 


\begin{tabular}{|l|l|}
\hline Categorias & \multicolumn{1}{c|}{ Critérios } \\
\hline \multirow{5}{*}{ Autonomia } & $\begin{array}{l}\text { Origem das proposições: identificação da iniciativa das } \\
\text { proposições e sua congruência com o interesse dos beneficiários } \\
\text { das políticas públicas adotadas. }\end{array}$ \\
\cline { 2 - 3 } & $\begin{array}{l}\text { Alçada dos atores: intensidade com que as administrações locais, } \\
\text { dentro de determinado território, podem intervir na problemática } \\
\text { planejada. }\end{array}$ \\
\cline { 2 - 3 } & $\begin{array}{l}\text { Perfil da liderança: características da liderança em relação à } \\
\text { condução descentralizadora do processo de deliberação e de } \\
\text { execução. }\end{array}$ \\
\cline { 2 - 3 } & $\begin{array}{l}\text { Possibilidade de exercer a própria vontade: instituições, normas } \\
\text { e procedimentos que permitam o exercício da vontade política } \\
\text { individual ou coletiva. }\end{array}$ \\
\hline \multirow{5}{*}{ Bem comum } & $\begin{array}{l}\text { Objetivos alcançados: relação entre os objetivos planejados e os } \\
\text { realizados. }\end{array}$ \\
\cline { 2 - 2 } & $\begin{array}{l}\text { Aprovação cidadã dos resultados: avaliação positiva dos atores } \\
\text { sobre os resultados alcançados. }\end{array}$ \\
\hline
\end{tabular}

Fonte: Elaborado pelos autores com base nos critérios da PEGS/FGV, a partir de Tenório (2012).

Salienta-se que, para efeitos deste artigo, analisou-se apenas a categoria Processos de Discussão.

Para identificar os critérios necessários para essa análise, elaborou-se um conjunto de questões norteadoras para as entrevistas, a observação e a análise documental (Quadro 3, inserido na próxima página). 


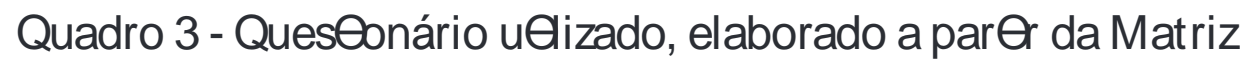

\begin{tabular}{|c|c|c|}
\hline Categorias & Critérios & Perguntas \\
\hline \multirow{7}{*}{$\begin{array}{l}\text { Processo de } \\
\text { discussão }\end{array}$} & Canais de difusão & $\begin{array}{l}\text { 1. Os participantes do COMUDE têm acesso } \\
\text { às informações da municipalidade? } \\
\text { 2. Que instrumentos são utilizados para a } \\
\text { disponibilização destas informações? } \\
\text { 3. Como estas informações são utilizadas } \\
\text { pelos participantes para fortalecer a } \\
\text { mobilização e/ou a discussão? }\end{array}$ \\
\hline & $\begin{array}{l}\text { Qualidade da } \\
\text { informação }\end{array}$ & $\begin{array}{l}\text { 4. Estas informações disponibilizadas são } \\
\text { suficientes para proporcionar equida- } \\
\text { de na discussão? } \\
\text { 5. São claras e objetivas? Satisfazem às } \\
\text { necessidades (são úteis)? }\end{array}$ \\
\hline & $\begin{array}{l}\text { Espaços de } \\
\text { transversalidade }\end{array}$ & $\begin{array}{l}\text { 6. Existem momentos de discussão com } \\
\text { outros espaços, isto é, há momentos } \\
\text { de integração com outros conselhos } \\
\text { setoriais do município? }\end{array}$ \\
\hline & $\begin{array}{l}\text { Relação com } \\
\text { outros processos } \\
\text { participativos }\end{array}$ & $\begin{array}{l}\text { 7. O COMUDE participa e/ou integra ou- } \\
\text { tros fóruns de discussão no município } \\
\text { ou na região? }\end{array}$ \\
\hline & Órgãos existentes & $\begin{array}{l}\text { 8. O conselho utiliza alguma estrutura já } \\
\text { existente no município para o seu fun- } \\
\text { cionamento, evitando, assim, a dupli- } \\
\text { cação? }\end{array}$ \\
\hline & $\begin{array}{l}\text { Órgão de } \\
\text { acompanhamento }\end{array}$ & $\begin{array}{l}\text { 9. Existe um mecanismo de controle das } \\
\text { atividades do conselho, assegurando } \\
\text { que o que foi implementado foi mes- } \\
\text { mo de acordo com o que foi decidido? }\end{array}$ \\
\hline & $\begin{array}{l}\text { Pluralidade do } \\
\text { grupo promotor }\end{array}$ & $\begin{array}{l}\text { 10. Existe um compartilhamento da lide- } \\
\text { rança entre os participantes no sentido } \\
\text { de mobilizar outros atores? }\end{array}$ \\
\hline
\end{tabular}

Fonte: Elaborado pelos autores com base nos critérios da Pegs/FGV, a partir de Tenório (2010).

\section{Processos de discussões nos Comudes do Corede-Norc}

Esta seção tem como objetivo apresentar como ocorre o processo decisório nas interlocuções dos atores envolvidos nas atividades dos Conselhos Municipais de Desenvolvimento dos municípios que pertencem ao Corede-Norc quanto à participação social nas questões voltadas ao desenvolvimento local/regional. A base para esta análise é a proposta de cidadania deliberativa da PEGS da Ebape, enunciada na metodologia, de acordo com o Quadro 2 e o Quadro 3.

A categoria Processos de Discussão, segundo Tenório (2012), é essencial para os procedimentos decisórios desenvolvidos nas esferas públicas ou na condução de 
políticas públicas, pois é na discussão que se institui o diálogo que verbaliza a compreensão que cada um tem do objeto em análise.A categoria tem como objetivo apresentar como ocorre o processo decisório no diálogo entre atores envolvidos nas atividades dos Conselhos Municipais de Desenvolvimento dos municípios que pertencem ao Corede-Norc quanto à participação social em questões voltadas ao desenvolvimento local/regional.

Esta categoria, como o nome sugestivamente indica, é o local de discussão de problemas através da autoridade negociada na esfera pública. Pressupõe igualdade de direitos e é entendido como um espaço intersubjetivo e comunicativo, que possibilita o entendimento dos atores sociais envolvidos. Segundo Jürgen Habermas (1997), apud Tenório (2007), a esfera pública não pode ser entendida como uma instituição, nem como uma organização, pois ela não constitui uma estrutura normativa capaz de diferenciar competências e papéis. Em outras palavras, afirma-se que a esfera pública se constitui essencialmente numa estrutura dialógica onde se busca o entendimento e está relacionada com o espaço social reflexivo gerado no agir comunicativo.

A categoria avalia os elementos condicionantes para um funcionamento efetivo dos conselhos, que estão presentes e instituídos legalmente nos onze municípios estudados, mas se observou que, desde a instituição gradativa desses conselhos, cuja maioria iniciou-se no ano de 2003, a finalidade destes espaços por parte dos integrantes da municipalidade ainda está pouco compreendida, e o agravamento da má compreensão pela população em geral gera uma ausência de ação efetiva por parte dos atores envolvidos, principalmente da sociedade, devido a essa incompreensão da necessidade de participação conjunta com o poder público.

\subsection{Canais de difusão}

Quanto à existência de uma ferramenta formal de disponibilização de informações por parte da municipalidade para o conselho, verificou-se que não existe um canal evidente de circulação de informação para mobilização dos participantes dos Comudes, como explica um dos entrevistados: "Olha, essas informações, elas não são assim de forma automática, elas são na medida em que são solicitadas" (PMCo).

Mas se observou, nos discursos dos atores, que existem condições favoráveis ao acesso às informações, conforme evidenciado na fala de PCBo: "[...] sempre quando eu precisei de uma informação, eles nos liberaram. Não tem restrição de a gente chegar e pedir uma informação [...]". Complementando, PMPa relata: "Nós temos uma gestão absolutamente transparente. Não tem nenhuma informação escondida aqui na administração municipal, então todos os membros do Comude, não só ele, porque nós temos 12,13 conselhos comunitários, e todos eles têm acesso sim às informações".

As entrevistam demonstram que essas informações não possuem formato específico e/ou especial, isto é, não existem relatórios ou prestações de contas destinados para os conselhos de maneira formal e principalmente regular, mas existe o acesso a canais de publicização comum aos cidadãos, como os murais oficiais de 
divulgação e programas de rádios, conforme pode ser observado na fala que segue:

Hoje nós temos um mural aqui que estão todas as publicações que acontecem, está no mural, então da seguinte forma e também os dois programas de rádio, tanto numa emissora quanto na outra, são publicados todos os acontecimentos, as notícias do município ali, então, a comunidade, a população também tem acesso através dos programas de rádio ( $\mathrm{PMBO}$ ).

Os portais eletrônicos também são utilizados para disponibilizar informações da administração pública municipal para a comunidade em geral e também para os conselheiros, tal como explica PMPa: "Especialmente no site da prefeitura e no site do próprio Comude, tem as informações que passam pelo Comude, e as informações gerais do município estão no site da prefeitura". Complementa outro entrevistado: "[...] hoje nós temos o site também, tem bastante informação" (PMAj).

Existe, ainda, o fornecimento de informações para os conselheiros, quando por eles realizados, excepcionalmente, pedidos de informação formal ao executivo: “[...] se o participante (conselheiro) fizer um pedido por escrito, o município dá a informação" (PCCa).

Explicam os entrevistados que aos instrumentos e formas de disponibilização, além dos já mencionados, ainda se acrescentam os documentos oficiais da prefeitura e um jornal de circulação local. "Nós divulgamos por meio de ofício aos que fazem parte da diretoria executiva e do conselho e divulgamos no jornal", explica PCAj. Da mesma forma, complementa PMCo que:

[...] existe a comunicação online, ou por meio físico, de fornecimento de documento, mais ou menos dessa forma que é feito essa comunicação e essa disponibilização de dados e informações. [...] Conforme é solicitado, não tem uma informação assim permanente. [...] naquilo que o Comude tem dúvida, ele solicita e recebe a informação instantaneamente, e não podia ser diferente também.

PCCa declara que as informações da municipalidade estão disponíveis para toda comunidade, e não exclusivamente para os membros dos Comudes e demais instâncias existentes no município, mas, por outro lado, observa que a busca pela informação deve partir do cidadão, o que não ocorre habitualmente, conforme o declarante narra: "Não são muito procuradas essas informações. É raro isso acontecer". Complementa PCAj: "[...] o envolvimento é muito pouco dos membros, tanto do Comude quanto da própria população".

Ou seja, nessas circunstâncias, acredita-se que as informações, quando procuradas e disponibilizadas, são muito pouco utilizadas pelos participantes para fortalecer a mobilização ou discussão das políticas públicas, pois não existe envolvimento ativo dos conselheiros e menos ainda da população em geral com os assuntos cotidianos da municipalidade.

Em consequência, evidenciou-se que as reuniões e as audiências dos conseIhos e de outros espaços públicos de discussão estão esvaziando, pois no Comude, mesmo os conselheiros estando munidos de informações, fica prejudicada a discussão em função dessa problemática (esvaziamento), pois se tem a informação, mas 
não se consegue desenvolver uma estratégia de ação e de trabalho por falta de gente, ressalta PCPa.

Aponta-se, para a atuação efetiva do conselheiro, o ingrediente responsável pelo fortalecimento da mobilização, pois, conforme explica $\mathrm{PClj}$, os atores com referendada atuação, em número reduzido, que, obviamente, são dedicados à busca do conhecimento, conseguem utilizar os dados do município e transformá-los em fontes de informação para alimentar as discussões, mas não é normal esta prática, pois o que acontece é uma passividade dos participantes, isto é, apenas participam da reunião, votam, mas não passa disso, não se substanciam de artifícios para argumentação.

As entrevistas evidenciaram também que os conselheiros, esporadicamente, utilizam as informações como base das discussões e fonte para estabelecimento de agenda pública, mas que, quando isso acontece, ressalta PCBo: "Tu podes fazer um levantamento bem preciso de como está o município. Isso ajuda na divulgação dos trabalhos. [...] por setor, é feito um levantamento do que pode ser melhorado, do que existe". Ou seja, raros são os momentos em que as informações são utilizadas para fomentar a discussão e apontar as prioridades, servindo como base para a elaboração das políticas públicas.

Destaca-se, ainda, a precariedade do funcionamento dos Comudes, pois o trabalho dos conselhos praticamente resume-se à execução do PPC, como explica PMAj (PPC - Participação Popular e Cidadã: nomenclatura utilizada no governo Tarso (2011-2014) para referir-se ao processo de participação da população na elaboração da Lei Orçamentária Anual - LOA). Ou, ainda, para alguma apreciação urgente que exija a participação da comunidade, complementa PCCo, e, mesmo nesse caso, as informações são poucas ou quase não são procuradas e/ou utilizadas para fortalecer a discussão.

\subsection{Qualidade da informação}

Quanto à diversidade, clareza e utilidade da informação proporcionada aos atores envolvidos, a situação percebida se agrava, pois as informações disponíveis, ou disponibilizadas, que circulam pela esfera pública não são enriquecidas com detalhes explicativos, para proporcionar um melhor entendimento por parte dos conselheiros, principalmente os indicados pela sociedade civil, visto que ficou evidente uma falta de capacidade cognitiva de muitos, para interceptar de maneira clara o que lhes foi informado/comunicado, isto é, para que essas informações possam ser utilizadas de maneira que possibilite uma equidade no diálogo, depende do nível de conhecimento das pessoas envolvidas.

Neste caso, questiona-se a qualidade das informações disponibilizadas e/ou fornecidas, conforme PCPa explica: "São claras (as informações) para quem tem conhecimento de política pública, [...] normalmente é num nível muito técnico" (grifos nossos). Problema referido por outro entrevistado: "Às vezes, as informações são muito técnicas; objetivas elas são, até objetivas demais" (PMCo). PClj complementa: 
A parte da legislação é complicada ... gera dúvidas, até nós já, em algumas reuniões, solicitamos a presença [...] de um advogado para esclarecer meIhor, então nós apontamos em alguma reunião do Codemi a necessidade de ter, dependendo da reunião, um setor jurídico, um assessor jurídico pra esclarecer a legislação, que deixa dúvida, com certeza, e você imagina uma pessoa representante de bairros que tenha uma formação limitada, às vezes ele tem dificuldade, ele tem limitação e conhecimento parcial, sem desmerecer o cidadão.

Dessa forma, as informações repassadas deixam de cumprir seu verdadeiro papel: a função niveladora, o que, consequentemente, acarreta tomada de decisões sem o devido conhecimento de causa, como menciona um dos entrevistados:

[..] as pessoas votam com o conhecimento superficial do assunto, não têm um estudo aprofundado. Eu acho que talvez o próprio participante, o próprio cidadão, ele é acomodado, ele não questiona muito, ele vota a partir de algumas informações, entende? Acho que também falta um compromisso de cidadania com quem faz parte do conselho ( $\mathrm{PClj}$ ).

Pode-se afirmar, então, que a falta de compreensão das informações, para proporcionar uma melhor igualdade de condições nas discussões, é decorrência do desinteresse da sociedade pela res pública e pela falta de conhecimento técnico de alguns participantes, como relata PCaj: "As informações seriam (úteis para a equidade), se as pessoas tivessem interesse em participar ou discutir, o que nem sempre acontece". Reflexão complementada por PMPa: "O que difere são os interesses de cada representante das entidades".

Outro fator que interfere na equidade das discussões é o fato dos representantes da municipalidade estarem mais envolvidos, mais próximos da gestão das políticas, e, assim, consequentemente, possuírem informações mais claras e transparentes e até em maior número, como explica um dos entrevistados:

Olha, talvez não seja suficiente (as informações para proporcionar equidade nas discussões) até porque não há uma, digamos, uma disparidade de conhecimento do bem, da coisa pública, os representantes governamentais, vamos dizer assim, no Comude, estão mais aparelhados, estão mais instrumentalizados, estão mais bem informados, estão mais acostumados com a linguagem da gestão, enfim, com as informações, então eu acho que, na minha opinião, os representantes governamentais no Comude, sejam da área que for, estão bem mais aparelhados, bem mais em condições de debater, sobrepondo-se, inclusive, aos demais. (PMCo, grifos nossos)

A partir destes apontamentos, o estudo revelou que as informações são disponibilizadas de maneira muito superficiais ou com terminologias e nomenclaturas técnicas, como o caso da legislação, dificultando o entendimento dos participantes pela falta de clareza e, muitas vezes, pela falta de objetividade, não satisfazendo, assim, as necessidades dos conselheiros para basilar sua argumentação e, por conseguinte, a tomada da decisão, que muitas vezes é realizada sem o conhecimento mínimo. 


\subsection{Espaços de transversalidade}

Quanto aos espaços que atravessam setores, com o intuito de integrar diferentes pontos de vista, ficou evidente que os Comudes do Corede-Norc não participam de outros espaços de discussão em seus municípios, não interagem diretamente com outros conselhos setoriais, embora se tenha buscado essa prática em alguns municípios, como explica um dos entrevistados: "Nós tentamos essa transversalidade, e não deu certo" (PClj). Porém, na composição dos Comudes, existem representações dos demais conselhos, ficando, dessa forma, restrita a este elo a questão da interatividade, como menciona PMCo: “Não, assim de forma muito, digamos, contundente, explícita, assim há uma discussão (com os demais conselhos), até porque o seguinte, o Comude tem representação de todos os conselhos municipais".

\subsection{Relação com outros processos participativos}

Quanto à interação com outros sistemas participativos já existentes na região, os Comudes mantêm uma relação, como, por exemplo, integrando a constituição da Assembleia Geral do Corede-Norc, e, assim, participando de eventos que este organiza e cuja participação solicita. Os Conselhos também participam da elaboração do PPA quando convidados. Salienta-se que, especificamente nos municípios de Panambi e Condor, que possuem aglomeração de empresas especializadas no ramo do agronegócio (pós-colheita), que constituem o Arranjo Produtivo Local (APL), os Comudes também participam dessas discussões, segundo PCCo.

O principal espaço que os Comudes integram e do qual participam na região é o do Sistema Estadual de Participação Popular e Cidadã (PPC), que é um processo aberto à participação universal da sociedade gaúcha e tem como objetivo contribuir para a elaboração do orçamento do Governo do Estado, sendo coordenado pelos Coredes e pela Seplag do estado do RS.

\section{5 Órgãos existentes}

Quanto ao uso de órgãos e estruturas já existentes, evitando a duplicação das estruturas, desde a constituição dos Comudes na região, em sua maioria no ano de 2003, são utilizadas as estruturas já existentes em seus respectivos municípios, isto é, a estrutura da prefeitura municipal, seja a física, como salas de reuniões, telefone, internet; pessoal: assessoria técnica contábil, jurídica, ou seja, não houve duplicação de estrutura para o estabelecimento de suas atividades.

\section{6 Órgão de acompanhamento}

Quanto à existência de um órgão que faça o acompanhamento de todo o processo, desde a sua elaboração até a implementação, garantindo a coerência e a fidelidade ao que foi deliberado de forma participativa, a pesquisa deixa claro e salienta que não existe um órgão que faça o acompanhamento das políticas públicas 
discutidas para garantir a coerência e a fidelidade ao que foi deliberado em plenário.

Percebeu-se uma questão importante durante as entrevistas no que diz respeito à moralidade dos atos, isto é, o que abona o que foi deliberado é exatamente o que foi decidido em plenário, ou seja, existe uma relação de confiança entre os atores, e a ferramenta de controle que garante esta coerência é o registro escrito, a ata da reunião, conforme explica um dos entrevistados: "É registrada (a decisão) em ata, nas atas de reunião do Comude" (PCPe, grifos nossos).

Também se observou os papéis exercidos pelas Diretorias Executivas dos conselhos neste aspecto, desempenhando a função fiscalizadora dessas deliberações e fazendo cumprir as decisões tomadas em plenário, como relata um dos entrevistados: "A própria direção do Comude se encarrega disso (do controle). Ela cobra, por exemplo, o cumprimento daquilo que foi decidido" (PMPa, grifos nossos).

\subsection{Pluralidade do grupo promotor}

Quanto ao compartilhamento da liderança, a fim de reunir diferentes potenciais atores, existem situações bem divergentes entre os conselhos. Ou seja, de um lado, há situações em que de fato existe uma partilha na forma de condução do processo, onde, em várias situações, como no PPC ou na elaboração do PPA, envolvem-se outras pessoas, para realizar o trabalho em conjunto, como ressalta um dos entrevistados:

Olha, sempre tem (comparehamento de liderança), é uma preocupação do Conselho, e eu senti isso agora, [...] essa nova diretoria que assumiu, ela parece que agora deu uma renovada, digamos assim, uma re-esquentada, digamos assim, ao nível de mobilização disso, do conselho, parece que ela está se encorpando mais, então há sempre uma mobilização, um chamamento de mais liderança, mais instituições para dentro do Comude, para dentro do Conselho (PMPe, grifos nossos).

De outro lado, há Comudes onde este compartilhamento não ocorre, em função da não participação dos atores nas atividades do conselho, permanecendo apenas a liderança responsável pelo processo.

\section{Conclusão}

A elaboração deste trabalho teve como finalidade, a partir dos critérios desenvolvidos, analisar os processos de discussão realizados nos Conselhos Municipais de Desenvolvimento - Comudes, nos municípios pertencentes ao Corede-Norc, visando ao fortalecimento da cidadania, a fim de promover o desenvolvimento regional, buscando analisar os procedimentos decisórios desenvolvidos nesses espaços públicos e a condução das políticas públicas locais.

A partir das informações obtidas por meio das entrevistas realizadas com os envolvidos e das análises da documentação e da legislação vigente em cada município, confrontadas com as discussões teóricas existentes, foi possível estabelecer algumas conclusões sobre o desempenho dos conselhos enquanto espaços de dis- 
cussão e deliberação das políticas públicas.

Nesse sentido, percebeu-se que os Comudes não exercem o que Habermas idealiza como cidadania deliberativa, pois, de acordo com o processo dialógico realizado nestes espaços, é realizado, sim, um compartilhamento da autoridade decisória com os participantes da ação, mas cabe a ressalva, pela análise realizada, que se deve levar em consideração, para a compreensão da proposta de estudo, as particularidades e especificidades individuais, ao analisar a categoria.

Ou seja, quanto aos espaços criados para discussão, percebe-se que os conselhos não foram capazes de formar uma esfera pública em um espaço gerencial deliberativo, pelo fato das instâncias participativas existentes caracterizarem-se como espaços onde demandas são levantadas pelos participantes, mas não como espaços capazes de sustentar negociações, debates e deliberações voltadas para um processo de construção conjunta e contínua para o bem comum de maneira a atingir o comum acordo.

Em relação aos processos de discussão, considerando a relação dos Comudes e o governo local dos municípios, assim como sua interação com outras instâncias de participação e controle social, considerando a intersetorialidade e transversalidade de algumas áreas e a relação dos mesmos com instâncias de outros entes federados ou outros sistemas de participação regional, constatou-se certa passividade no que tange a seu relacionamento com outros órgãos, conselhos ou outros espaços regionais de participação, encontrando-se muito aquém do desejado ou visionado pelo estilo habermasiano de cidadania deliberativa, pois os Comudes não participam de outros espaços locais de discussão e, assim, consequentemente, não interagem com os outros conselhos setoriais, embora pontualmente, em alguns municípios, tenha-se tentado essa alternativa.

O que existe é o que classificamos como sendo uma "interatividade limitada" com esses espaços, pois muitos conselheiros fazem parte também da composição dos demais conselhos setoriais. Regionalmente, os Comudes integram legalmente a composição do Corede, sendo representados neste espaço regional pelo presidente, mas observou-se que, na prática, não há uma interação consistente a ponto de gerar resultados significativos.

Destaca-se que os municípios que integram o Corede-Norc são de pequeno porte, com exceção de ljuí, que possui em torno de 80 mil habitantes, segundo o censo do IBGE de 2010, os quais necessitam promover uma maior articulação da comunidade para atuarem no Comude, considerado um espaço público de orientação geral para a atuação dos demais conselhos setoriais.

Ressalta-se também que as pessoas precisam se envolver nas atividades do conselho para expor suas necessidades sentidas e vivenciadas. Para tanto, também é necessário um investimento por parte do Poder Público no sentido de capacitar os membros que atuam no conselho, assim como os potenciais atores, isto é, a população em geral, para se tornarem sujeitos ativos do desenvolvimento local/regional.

$\mathrm{E}$, ainda como proposta, deve-se elaborar uma estratégia de motivação para as pessoas afastadas do processo e também uma estratégia de fomento para aquelas que ainda não integram o grupo, para potencializar a participação e a ocupação 
destes espaços. Por conseguinte, é preciso melhorar e intensificar a organização dos conselhos, seja no sentido das comunicações interna e externa, na quantidade e qualidade das informações existentes e circuladas, preparando, assim, as pessoas para assumirem verdadeiramente o seu papel como cidadãos, assim como melhorar a interação com outros espaços transversais e setoriais no sentido de determinar avanços em termos concretos de resultados para a coletividade.

Em suma, o estudo revelou que os Comudes atingem os objetivos propostos na sua origem, pois, mesmo com certa dificuldade e resistência de alguns gestores, esses conselhos contribuem em algum aspecto para a promoção do desenvolvimento local/regional, integrando as ações do poder público com as organizações privadas e a sociedade civil no sentido de melhorar a qualidade de vida da população. Além de ter sido evidenciado um desempenho insuficiente no exercício das suas competências de promover a participação de todos os segmentos da sociedade local, organizadas ou não, na discussão dos problemas e na identificação das potencialidades, bem como na definição de políticas públicas de investimento e ações que visem ao desenvolvimento acelerado dos municípios, também pecam na organização e na realização de reuniões e audiências públicas necessárias, pois devem oferecer mais e melhores espaços para que a sociedade possa discutir e eleger as prioridades municipais.

Pesa ainda a ausência dos Comudes na participação/elaboração dos Planos Estratégicos de Desenvolvimento dos municípios, pois se identificou essa lacuna dos conselhos na promoção e fortalecimento da participação da sociedade civil, no intuito de buscar uma integração regional, realizando, nesse aspecto, uma conexão com as atividades do Corede-Norc para buscar melhor articulação com o Estado e a União.

Os Comudes ainda não têm capacidade de se constituir num espaço de discussão e formulação de propostas para servirem como subsídio ao PPA, LDO e orçamentos municipais e estadual, no aspecto que tange à insuficiência da participação e, consecutivamente, na ausência de proposições de ações por parte da sociedade civil, além do não acompanhamento e fiscalização integral das ações ou investimentos que são discutidos no conselho.

Porém, é importante esclarecer que, apesar de os Comudes não atingirem o ideal habermasiano, de acordo com a pesquisa, evidenciou-se a evolução desses espaços na condução dos processos de tomada de decisão descentralizada, mostrando o esforço que os atores envolvidos dedicam à consecução de uma gestão envolvente das políticas públicas, na tentativa de mobilizar cada vez mais a sociedade, para melhorar constantemente os resultados que a gestão pública gera no cotidiano da população regional, ou seja, estes espaços públicos de discussão ainda precisam ser melhorados, seja no sentido da participação mais efetiva da sociedade como também na elaboração de estratégias que, através do diálogo, busquem o entendimento unânime, e que assim se evolua no processo decisório, isto é, que se ultrapasse o modelo tradicional de tomada de decisão utilizado: o voto.

Com a realização do estudo sobre os processos de discussões nos Comudes, pôde-se sentir a necessidade de alguns aprofundamentos em relação ao seu desempenho, visto que, com exceção do Codemi ljuí, os demais conselhos foram criados na região há apenas 10 anos. Nesse sentido, sugere-se a realização de estudos sobre a 
mensuração do impacto gerado pelas políticas públicas elaboradas e acompanhadas pelos conselhos, assim como um estudo dirigido para a identificação de possíveis variáveis sobre o baixo ou pouco envolvimento direto da sociedade civil nestes espaços.

\section{Referências}

ALLEBRANDT, S. L. A participação da sociedade na gestão pública local e na produção das políticas públicas: a atuação dos conselhos municipais de ljuí - RS, de 1989 a 2000. Ijuí: Unijui, 2002.

. Cidadania e Gestão do Processo de Desenvolvimento: um estudo sobre a atuação dos conselhos regionais e municipais de desenvolvimento do Rio Grande do Sul, de 1990 a 2009. Tese (Doutorado em Desenvolvimento) - Universidade de Santa Cruz do Sul, Santa Cruz do Sul, 2010.

DUARTE, Y. A. Brasil. Moradias, Cuidadores e Atendimento Domiciliar. In: SERVIÇO SOCIAL DO COMÉRCIO (SESC). Encontro Internacional de Gerontologia Social. São Paulo: SESC, 2006. p. 231-239

MARCONI, M. A.; LAKATOS, E.M. Técnicas de Pesquisa. 6. ed. São Paulo: Atlas, 2006.

MINAYO, M. C. S. O Desafio do Conhecimento: pesquisa qualitativa em saúde. 6. ed. São Paulo: Hucitec, 1999.

TENÓRIO, F. G. (Org.). Cidadania e Desenvolvimento Local. Rio de Janeiro: FGV; ljuí: Unijui, 2007.

- (Org.). Cidadania e Desenvolvimento Local: Critérios de Análise.

Rio de Janeiro: FGV; 2012.

. Descentralização Político-Administrativa, Gestão Social e Participação

Cidadã. In: DALLABRIDA, V. R. (Org.). Governança Territorial e Desenvolvimento. Rio de Janeiro: Garamond, 2011. p. 73-93.

. Metodologia de construção dos critérios para a avaliação de processos decisórios participativos deliberativos na implementação de políticas públicas. In: ENAPEGS, 3, 2009, Juazeiro. Anais... ENAPEGS, 2010. 